\title{
Application of the spatial division multiplexing technique in cooperative mimo systems
}

- Vo Khac Thanh

University of Science, VNU-HCM

- Bui Huu Phu

DCSELAB, University of Technology, VNU-HCM

- Tran Cong Hung

Post and Telecommunications Institute of Technology in Hochiminh City

(Manuscript Received on December 11 ${ }^{\text {th }}$, 2013; Manuscript Revised July 25 ${ }^{\text {th }}$, 2014)

\section{ABSTRACT:}

Cooperative MIMO is a combination technique between the single antenna cooperation communications and multipleinput multiple-output systems to achieve the advantages of traditional MIMO. In this paper, we focus on model that combines the spatial multiplexing technique and the cooperative communications, with relay nodes using decode and forward technique where source node and the relay nodes have only one antenna, destination node has multiple antennas; and relay nodes use amplify and forward technique to reduce power consumption and suitable for compact devices; and destination node uses zero forcing (ZF) algorithm. Finally, we show our simulation results in applying the spatial division multiplexing technique in cooperative mimo systems.

Keywords: SDM, MIMO-SDM, Cooperative MIMO, Cooperative communication.

\section{INTRODUCTION}

Nowadays, the demand of using broadband services and high-speed wireless platform is growing very fast, so the radio spectrum resources are running out. To overcome the issue, the multiple-input multiple-output (MIMO) technique, which uses multiple antennas at the transmitter and the receiver, is a promising technique to meet the demand to improve the quality and channel capacity of systems without increasing the transmit power and the frequency bandwidth
[1][2]. However, the implementation of MIMO systems on mobile terminals (referred to as MS) has to solve many challenges such as small size, limited energy, channel correlation, [3].

There are many previous research works focusing on spatial diversity to increase quality, but rarely consider the increase of the system capacity [4]. Therefore, the purpose of our paper research is to examine the model combining the spatial division multiplexing technique and the 
single antenna cooperative communications to create virtual spatial multiplexing MIMO systems [4-7]. In the paper, we also mention about the optimum power allocation (between the source node and the relay nodes), in order to maximize the quality of the systems [8].

This paper is divided into five parts as followings. After a brief introduction, an overview of the spatial division multiplexing technique and cooperative MIMO systems is described in section II. In section III, we present the model of cooperative MIMO systems using the spatial division multiplexing techniques. The results and discussion of our model will be shown in section IV. Conclusions are presented in final part.

\section{OVERVIEW OF SPATIAL DIVISION MULTIPLEXING TECHNIQUE AND COOPERATIVE COMMUNICATIONS}

Spatial division multiplexing (SDM) technique applying to MIMO systems, as shown in Fig. 1 performs the split of the transmit information bit into smaller sequence, and then transmits signals independently and simultaneously with same data resources on transmit antennas. So, this technique helps to increase system capacity.

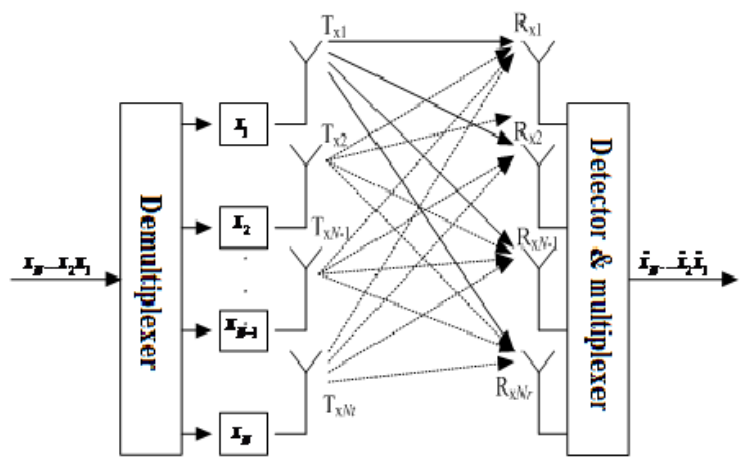

Fig. 1. SDM system model
At the receiver, a receive detector is used to detect signals from inter-stream interference. There are many techniques that are applied as spatial filtering (SF), BLAST, Zero Forcing, Minimum Mean Square Error (MMSE), etc.

Although spatial division multiplexing and transmit diversity have advantages for the base stations of cellular mobile communication, but they have some challenges in mobile stations due to the limits on the size, cost and complexity of hardware. Therefore, it is proposed a new technique, called cooperative communications. It allows mobile terminals using only one antenna but has the advantage of MIMO techniques by sharing antennas of other users together to make virtual MIMO systems, Thus, will improve the capacity and quality of the system. In cooperative MIMO system, the independent transmission line between a user and the base station is done via a relay channel as shown in Fig. 2.

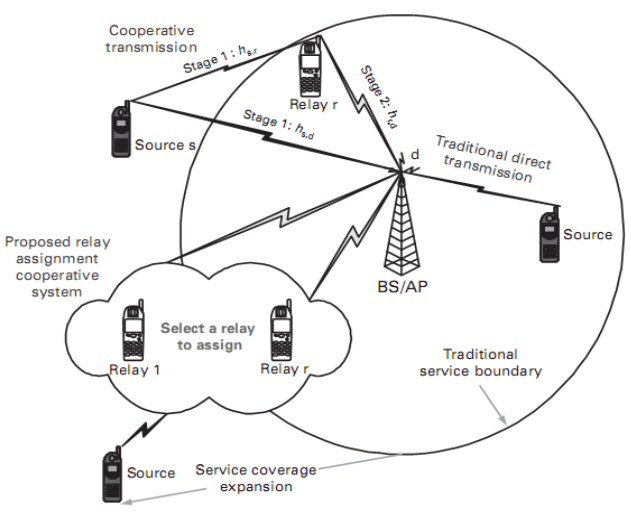

Fig. 2. Cooperative Communication model

Cooperative process divided into two orthogonal phase (to avoid interference between two phases) as follows:

+ Phase 1: The source node sends information to 
destination node and relay nodes simultaneously.

+ Phase 2: Relay node sends information to the destination node

The purpose of cooperative communication techniques that improve the quality of transmit signal from the source node to the destination node, specifically through improved BER at the receiver of the system. Thus, the signal processing techniques need to be selected and combined so that the system gain levels of maximum diversity.

\section{PROPOSED MODEL OF COOPERATIVE MIMO SYSTEMS}

In the previous section, we can find that the benefits of spatial multiplexing can be achieved with the terminal has only one antenna, and known as Cooperative Spatial Multiplexing (CSM). In this section, we propose the CSM model as shown in Fig. 3.

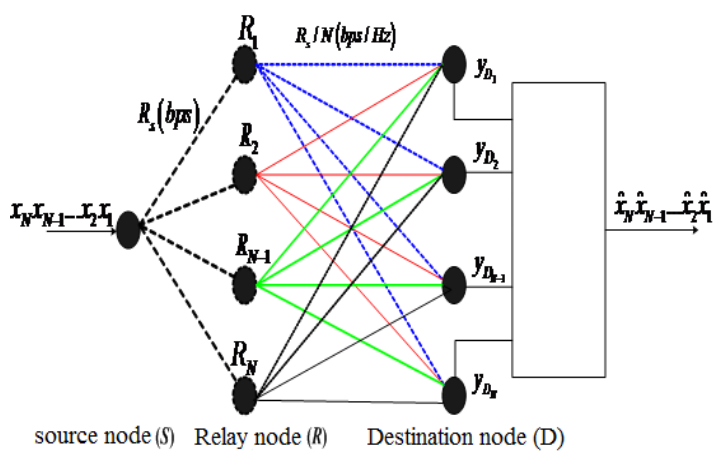

Fig. 3. Cooperative spatial multiplexing model

The specification of CSM model as follow:

+ A source node, a destination node and $\mathrm{N}$ relay nodes.

+ Source node and relay nodes have only one antenna at each node, create a virtual antenna array
+ The source node transmits the signal to the relay nodes

+ The relay nodes perform amplify and only forward a pre-select of the received signal with the gain $\beta$ to the destination node with lower transmission rate to take the advantages of the system capacity MIMO systems.

+ Destination node, as base stations, multiple antennas are installed, (larger than the relay node), the rejection and restore the original signal is transmitted from the source node.

+ All relay nodes must be synchronized with each other completely to ensure the receiving and transmitting simultaneously.

+ Channel between nodes is Rayleigh channels, flat and slow.

+ Total transmit power of the entire system is tied to a fixed rate.

At time slot $\mathrm{t}$, source node broadcasts the data sequence $\mathrm{x} 1 \mathrm{x} 2 \ldots \mathrm{xn}$ to $\mathrm{N}$ relay nodes $\mathrm{R} 1, \mathrm{R} 2, \ldots$, $\mathrm{Rn}$ with the same output power as Ps and Rs speed (bps). Each relay node $\mathrm{Ri}$ only receive a transmitted signal $\mathrm{x} 1$. This method is done by using time controllers - each relay node $\mathrm{Ri}$ is only enabled for operation in a ith time passed the first stage of the fisrt transmittion. The signal received by the ith relay node in the ith time slot is characterized by the following expression:

$$
y_{R_{i}}=h_{S R_{i}} x_{i}+n_{R_{i}} \text {, }
$$

where $h_{S R_{i}}$ is the channel ratio between the source node and the ith Relay nodes, $n_{R_{i}}$ is AWGN white noise with zero mean value and 
variance is $\mathrm{N} 0 / 2$ corresponding to each direction, transmitted signal $\mathrm{xi}$ have the energy is $R_{s} / N(b p s)$.

In the next phase, all of the Relay nodes will be amplified and forward the data was received earlier. This is the Relay nodes in the same cell, the correlation distance between nodes is:

$$
d_{S D}=d_{S R}+d_{R D}
$$

This means that all the relay nodes will be assumed have equal distance to the source node, the ith relay node $(1<\mathrm{i}<\mathrm{N})$ only transmit $(\mathrm{tN}+\mathrm{i})$ th bit from xi signal which received in every time slot $\mathrm{t}>0$. Each relay node Ri will amplify receive signal with gain parameter is $\beta$ which satisfy the constrains of transmit power of relay node is $\mathrm{Pr}$ before forwarding to the destination node.

During data forwarding, the data rate is reduced to the $R_{s} / N(b p s)$ in order to exploit the capacity of MIMO communication.

ith relay node only amplifies the only preselected receive signal, plus noise $\beta_{y R_{i}}$, and forward simultaneously to the destination node with transmission power is $\mathrm{Pr}$, in the time slot $(\mathrm{t}+1)$ with data rate is $x_{i} \in\left\{+\sqrt{E_{s}},-\sqrt{E_{s}}\right\}$. Therefore the bits energy in source node is ES $=\mathrm{PS} / \mathrm{RS}$, and in the relay nodes is $\mathrm{ER}=\mathrm{N} . \mathrm{PR} / \mathrm{RS}$. So the model which we use has 4 rely nodes that mean the transmission speed in the CSM by 2 times the speed of SISO to achieve the same spectral efficiency, when the total transmit power of system is (PS + NPR) is kept at the fixed power P. That mean:
(3) $P=P_{s}+N P_{r}$

Thereforce, when increasing the transmit power PS will increase the reliability of the SR channel, but reduces the power allocated to the relay nodes leading to the restoration of the signal at the destination nodes less reliable. Conversely, reducing the capacity of power PS allow power allocated to the relay nodes increases, but the poor quality on the SR channels. So we expect that there exists a pair of PS and PR values so that the optimal minimum error probability at the destination nodes (ie, maximizing the quality of the system).

The receive signal at the $\mathrm{jth}$ antenna $(\mathrm{j}=1,2, \ldots$, $\mathrm{M})$ of the destination node is expressed as follows:

$$
y_{D}=\sum_{i=1}^{N} g_{D R} \beta_{i} y_{R}+n_{D},
$$

where $\mathrm{dDR}$ is distance between relay node $\mathrm{Ri}$ and the destination node $\mathrm{D}$. The receive signal at the destination node $\boldsymbol{y}_{D}=\left[y_{D}, y_{D}, \ldots, y_{D}\right]^{T}$ can be abbreviated to following equaltion:

$$
\boldsymbol{y}_{D}=\mathbf{G} \mathbf{x}+\mathbf{N}_{D},
$$

where:

$$
\begin{gathered}
G_{j, i}=\beta_{i} g_{D R} h_{R S}, \\
N_{D}=\beta_{i} g_{D R} n_{R}+n_{D},(7) \\
\boldsymbol{x}=\left[x_{1}, x_{2}, \ldots, x_{N}\right]^{T}, \\
\hat{\boldsymbol{x}}=\left[\hat{x}_{1}, \hat{x}_{2}, \ldots, \hat{x}_{M},\right]^{T},(9) \\
\mathbf{N}_{D}=\left[N_{D}, N_{D}, \ldots, N_{D}\right)^{T 10)} \\
i=1,2, \ldots, N \quad j=1,2, \ldots, M .
\end{gathered}
$$

The transmit power of relay nodes is defined as Pr:

\section{Trang 8}




$$
\begin{aligned}
P_{r} & =\overline{\beta_{i}^{2} y_{R}^{2}} \\
& =\beta_{i}^{2}\left[\overline{\left|h_{R S}\right|^{2}} P_{s}+N_{0}\right]
\end{aligned}
$$

From this inferred amplification coefficient $\beta \mathrm{i}$ :

$$
\beta_{i}=\sqrt{\frac{P_{r}}{\left.\overline{\left[\left.h_{R S}\right|^{2}\right.} P_{s}+N_{0}\right]}} .
$$

Amplification coefficient $\beta$ changed by a fading coefficient $h_{S R_{i}}$ on SR channel and thus noise also amplified by $\beta$ coefficient.

At the receiver, the small sequences after detected will be multiplexed with each other. Transmit signal vector $\boldsymbol{x}=\left[x_{1} \ldots x_{N}\right]^{T}$, $\boldsymbol{y}=\left[y_{D_{1}} \ldots y_{D_{n}}\right]^{T}$ receive signal vector, noise vector at the receiver $z=\left[z_{1} \ldots z_{N}\right]^{T}$, channel matrix between transmitter and receiver is:

$$
\boldsymbol{H}=\left[\begin{array}{cccc}
h_{11} & h_{12} & \ldots & h_{1 N} \\
h_{21} & h_{22} & \ldots & h_{2 N} \\
\cdot & \cdot & \cdot & \cdot \\
\cdot & \cdot & \cdot & \cdot \\
\cdot & \cdot & \cdot & \cdot \\
h_{M 1} & h_{M 2} & \ldots & h_{M N}
\end{array}\right] .
$$

The system equation can be expressed as follow:

$$
\boldsymbol{y}=\boldsymbol{H} \boldsymbol{x}+\boldsymbol{z}
$$

From receiver vector $y$, the receiver using the detector to detect transmit signal vector $\hat{\boldsymbol{x}}$. We have many detection algorithms for detect signal at receive antenns such as: Zero forcing $(\mathrm{ZF})$, Minimum Mean Square Error (MMSE), etc.

\section{THE SIMULATION RESULTS OF SYSTEMS}

We perform simulation and evaluation of the system quality through BER and capacity parameters of AF-CSM system under many different conditions such as total transmit power constraints, changing the relative position of the relay nodes and power allocation between the source node and the relay node. In addition, the quality of the AF-CSM system is compared with other systems such as SISO, traditional V-BLAST, and especially CSM system using DF at the relay node. For fair and accurate, the totaltransmit power of all system and are assumed to be $P$.

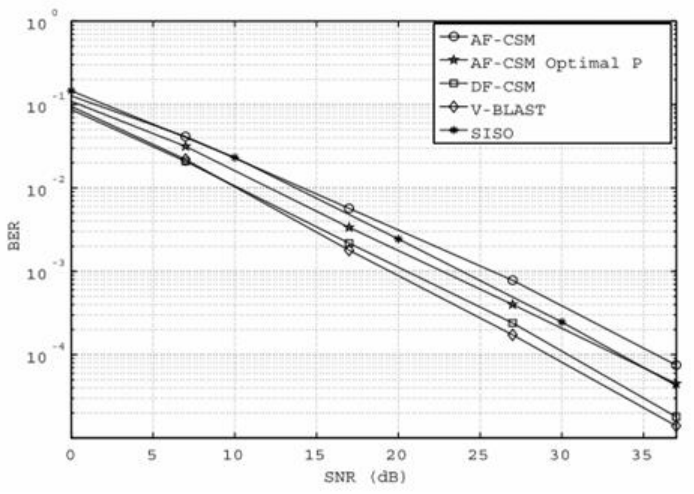

Fig. 4. BER Comparison of AF-CSM with other systems

A comparison of BER performance between AF-CSM system with other systems is shown in Fig. 4. It can be seen that the quality of the AFCSM system is better than other ones. However, when the parameters unchanged and applied to the power distribution system of CSM, we can see the quality of the AF-CSM system is significantly improved and better SISO. 


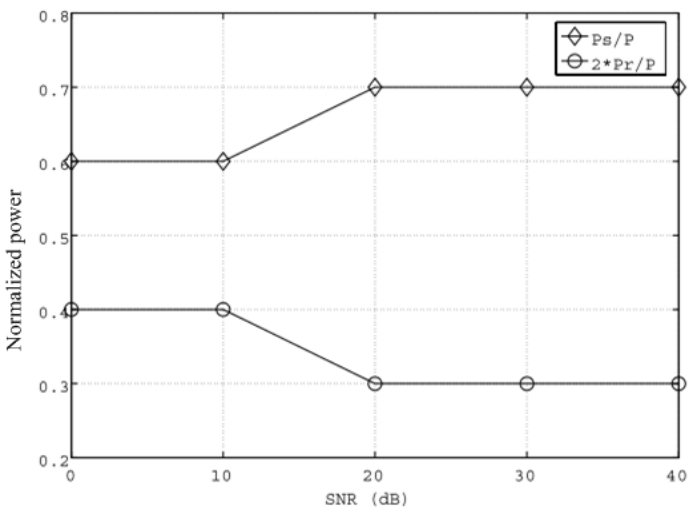

Fig. 5. Power distribution of AF-CSM system.

Next, we go to the trend of the power distribution of the AF-CSM system in Fig. 5. In the figure, we illustrate the distribution of power within the system in order to minimize the amount of BER (maximum quality system), the standardized distance between the source node and the destination node is 0.5 . Through figure we can see most of the transmit power tends to focus on source node to optimize system quality .This means that the SR channels are very sensitive channels and have a huge impact on the quality of the system.

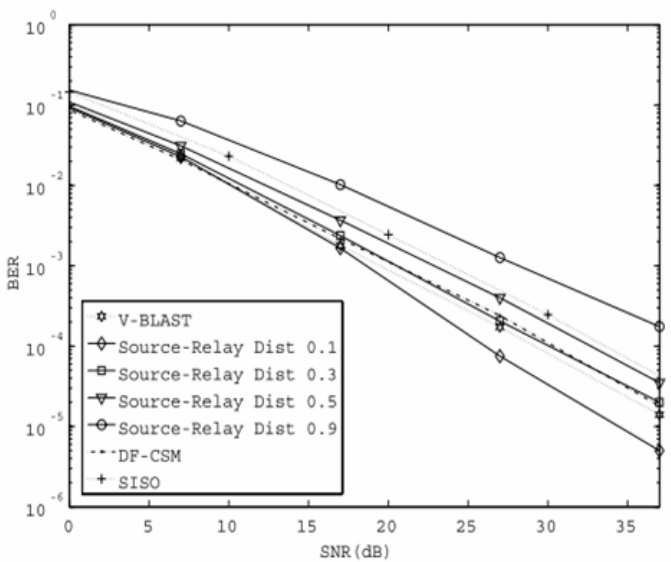

Fig. 6. Power distribution of AF-CSM system

The quality AF-CSM system when applying the optimal power allocation to minimize BER and change the position of the relay nodes is shown in Fig. 6. We can see that the quality of our system improve gradually when reduce the distance between source node and the relay node. Especially, when distance is 0.1 (normalized distance), the quality of the AF-CSM system better than traditional V-BLAST. Thus, it can be concluded that channel quality between source node and the relay nodes decides significantly to the quality of the whole system.

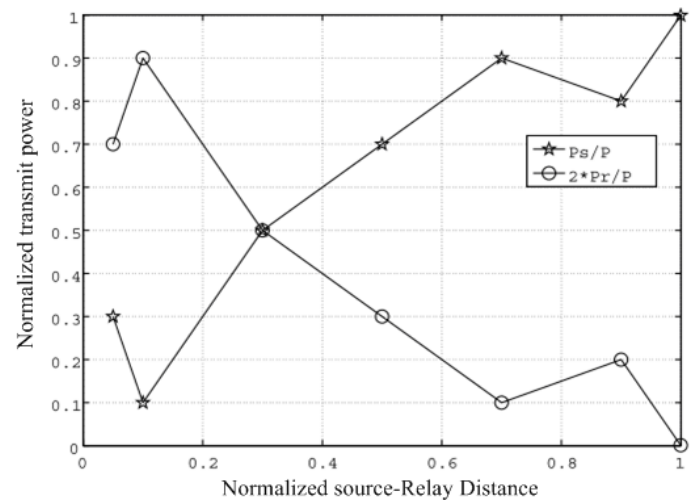

Fig. 7. Simulation results of optimal power allocation, $\mathrm{SNR}=40 \mathrm{~dB}$.

The optimal power allocation between source node and the relay nodes corresponding binding agreement with normalized SR distance is shown in Fig. 7. Based on the results shown in the figure, we can see when the SR distance increasing, the transmit power at source node must also increase (respectively, the transmit power at the relay nodes descending) ensure good quality on SR channel. This will help the relay nodes has better channel estimation and thus minimizing the bit error rate of BER and maximize overall system quality. 


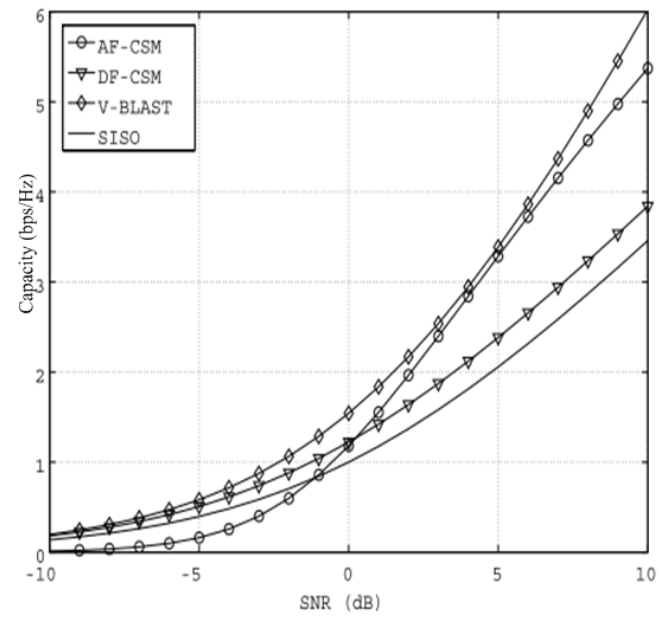

Fig. 7. The capacity results of $2 \times 2$ AF-CSM system compared with other systems.

Capacity of the AF-CSM $(1 \times 2 \times 2)$ system compared with other systems is illustrated in Fig. 7. When the SNR is small $(<0 \mathrm{~dB})$, the capacity of AF-CSM is very small, even smaller than SISO. However, the capacity of the AF-CSM increases as SNR increases, and through figure, we can see when the SNR> $2 \mathrm{~dB}$, the capacity of the AF-CSM significantly improved and larger capacity of SISO, DF-CSM. At the same time, when SNR> 5 $\mathrm{dB}$, the size of the AF-CSM Proximity to the capacity of V-BLAST system.

Through the simulation results, we also see the important role of the SR channels in developing AF-CSM system. Accordingly, to improve quality of AF-CSM systems, the methods used to ensure quality in the SR channel is necessary. A number of methods can be used as encryption, or select some relay nodes near the source node to forwarding signal.

\section{CONCLUSIONS}

This has conducted research overview spatial division multiplexing, cooperative MIMO system, the digital signal processing at the relay nodes and separation / recovery signal at the destination node. The paper also proposed a model of cooperative MIMO system using the algorithms of spatial division multiplexing for both relay node and destination node.

ACKNOWLEDGMENTS: This research is supported by National Key Laboratory of Digital Control and System Engineering (DCSELAB), HCMUT, VNU-HCM under grant number 102.02-2011.23 


\section{Úng dụng kỹ thuật ghép kênh phân chia theo không gian trong hệ thông MIMO hợp tác}

- Võ Khắc Thành

Trường Đại học Khoa Học Tự Nhiên, ĐHQG-HCM

- Bùi Hữu Phú

DCSELAB, Trường Đại học Bách Khoa, ĐHQG-HCM

- Trần Công Hùng

Học Viện Công Nghệ Bưu Chính Viễn Thông

\section{TÓM TÁT:}

Kỹ thuật MIMO hợp tác là kỹ thuật kết hợp truyền thông giữa các thiết bị đầu cuối đơn anten nhằm đạt được các ưu điểm của hệ thống MIMO truyền thống. Trong bài báo này chúng tôi tập trung vào mô hình kết hợp kỹ thuật ghép kênh không gian của MIMO vào truyền thông hợp tác tạo thành hệ thống MIMO hợp tác, với nút chuyển tiếp dùng kỹ thuật giải mã và chuyển tiếp (DF-Decode and forward) với các đặc điểm sau: nút nguồn và nút chuyển tiếp chỉ có một anten, nút đích có nhiều anten; nút chuyển tiếp dùng kỹ thuật khuếch đại - chuyển tiếp nhằm giảm thiểu công suất tiêu thụ và phù hợp với các thiết bị nhỏ gọn và nút đích dung kết hợp bộ thuật toán ZF. Cuối cùng chúng tôi xin trình bày kết quả mô phỏng trong việc ứng dụng kỹ thuật ghép kênh phân chia trong không gian cho hệ thống MIMO hợp tác.

Từ khóa: SDM, MIMO-SDM, MIMO Hợp tác, Truyến thông hợp tác.

\section{REFERENCES}

[1]. A. Darmawan, Cooperative Spatial Multiplexing System, in Iowa State University, 2004.

[2]. G.D. Golden, G.J. Foschini, R.A. Valenzuela, and P.W. Wolniansky, Detection algorithm and initial laboratory results using the V- BLAST space-time communication architecture, Electron. Lett., vol. 35, no. 1, pp.1415, 1999.

[3]. K. J. Ray Liu, Ahmed K. Sadek, Weifeng Su, Andres Kwasinski, Cooperative
Communications and Networking, Cambridge University Press, 2009.

[4]. Dohler, M., Lefranc, E., Aghvami, H., Space-time block codes for virtual antenna arrays,Personal, Indoor and Mobile Radio Communications, 2002. The 13th IEEE International Symposium on, pp.414 - 417 vol. 1, Sept. 2002

[5]. A. Darmawan, S. W. Kim, and H. Morikawa, Amplify-and-Forward Scheme in Cooperative Spatial Multiplexing, in

\section{Trang 12}


Mobile and Wireless Communications Summit, 2007. 16th IST, 2007, pp. 1-5.

[6]. Bletsas A., et al., A simple cooperative diversity method based on network path selection,"IEEE Journal on Selected Areas in Communications, vol. 24, no. 3, pp.659672, 2006.

[7]. B. Sklar, Rayleigh fading channels in mobile digital communication systems part
I: Characterization, IEEE Communications Magazine, July, 1997.

[8]. P. W. Wolniansky, et al., V-BLAST: an architecture for realizing very high data rates over the rich-scattering wireless channel, in Signals, Systems, and Electronics, 1998. ISSSE 98. 1998 URSI International Symposium on, 1998, pp. 295-300. 